\title{
Texto ou discurso?
}

BRAIT, B; SOUZA-E-SILVA, M. C. (orgs.) Texto ou discurso? São Paulo: Contexto, 2012. 302 p.

Thays Caroline Barroca Ribeiro Morettini*

Na apresentação da obra Texto ou discurso? (2012), Beth Brait e Maria Cecília Souzae-Silva discutem a complexidade das reflexões exigidas para se compreenderem os termos texto e discurso. As autoras ressaltam que a obra apresenta pontos de vista teóricos e metodológicos diferenciados, revelando distintas concepções e formas de abordagens da linguagem.

No percurso dos 14 capítulos que compõem o livro, é analisada e discutida, de forma pontual, a distinção entre texto/discurso, bem como sua interdependência. As reflexões desencadeadas nesta obra permitem que o leitor/pesquisador compreenda as dimensões teóricas e práticas do conceito de texto e de discurso, tendo em vista a abordagem da funcionalidade dos conceitos em discussão.

No capítulo inicial, intitulado "Perspectiva dialógica”, Brait trata da concepção de texto e de discurso desenvolvida nos trabalhos do Círculo de Bakhtin. A autora busca evidenciar como os conceitos de texto e discurso concretizam a concepção bakhtiniana da linguagem.

Brait analisa trabalhos de diferentes épocas desenvolvidos por Bakhtin e Voloshinov. Com isso, a autora discute o texto e sua dimensão semiótico-ideológica, considerando a produtividade na Linguística e em outras ciências. O objetivo da autora é articular reflexões a respeito do texto e do discurso desenvolvidas por Bakhtin e Voloshinov em trabalhos de épocas distintas. Após as análises de alguns trabalhos dos autores mencionados acima, Brait empreende revelar o lugar da Filosofia da Linguagem na unidade da visão marxista do mundo.

Ao revisitar os trabalhos bakhtinianos, a pesquisadora discute a concepção de texto como sendo dependente do todo do enunciado e analisa as fronteiras entre o texto e o contexto.

Brait encerra seu capítulo aplicando alguns pressupostos oferecidos pelo pensamento bakhtiniano para a compreensão do texto/discurso e analisa a canção "Bola dividida”,

\footnotetext{
* Mestranda pelo Programa de pós-graduação em Letras/Estudos Literários, da Universidade Estadual de Londrina (UEL).
} 
interpretada por Zeca Baleiro. A autora conclui que alguns aspectos da materialidade verbal auxiliam na compreensão dos discursos que constroem o texto.

Em “Peregrinações de um testemunho”, Danielle Zaslavsky versa sobre o processo de midiatização de um caso que ocupou a imprensa mexicana durante os primeiros meses do governo do presidente Calderón. O caso refere-se a uma mulher de 73 anos, indígena e pobre, que morreu em um hospital regional após um estupro coletivo cometido por militares.

Neste capítulo, a autora visa a tratar da inexorabilidade do mercado linguístico, no qual a tradução viu-se diretamente impelida a questionar o significado do testemunho de uma anciã moribunda. A análise da autora fundamenta-se em um corpus de imprensa oriundo de quatro jornais de circulação nacional do México: La Jornada, El Universal, Milenio e Reforma.

Zaslavsky analisa o corpo destes textos a fim de compreender a construção dos atores e os objetos tematizados em seus discursos. Ao tratar das vicissitudes de um testemunho e estabelecer um contraponto entre tradução literal e argumentação jurídica de um relatório colocado à disposição do público, a autora conclui que a midiatização do caso jurídico acabou provocando uma encenação em que a contraposição das vozes discursivas respondiam-se mutuamente. Ao realizar sua análise, a autora conclui que foi possível revelar as estratégias argumentativas adotadas por diferentes vozes, com a finalidade de cada qual poder defender a sua verdade.

Décio Rocha, no capítulo seguinte, discorre sobre a perspectiva foucaultiana para tentar compreender o texto e o discurso. $\mathrm{O}$ autor discute o que está em jogo quando se tematiza a passagem do texto ao discurso. Por meio desta indagação, Rocha situa a iniciativa empreendida por Foucault referente à reflexão sobre o discurso, atualizada à época da obra Arqueologia do saber (1986). Ao estabelecer o contraponto do plano textual ao discursivo, o autor trata de alguns trabalhos escritos por Foucault, tendo por base a conceptualização de discurso do filósofo francês. Ao pensar as bases para um plano discursivo, Rocha afirma que Foucault, ao desenvolver contínuas reformulações sobre o conceito de discurso, buscou lograr a criação de uma definição que se distanciasse progressivamente da noção de texto. $\mathrm{O}$ autor considera que a análise de um corpus não é o ponto central de seu trabalho e, por fim, declara que o intento de sua pesquisa foi justamente o de discutir a abordagem discursiva de Foucault. Assim, Rocha analisa o plano discursivo de um folder da campanha publicitária de um condomínio de apartamento da Barra da Tijuca, no Rio de Janeiro. Rocha conclui que o viés discursivo permite 
atualizar uma linha de fuga em relação às convenções da análise textual, a qual se propõe a analisar as verdades presentes na materialidade dos textos.

No capítulo “Cor e sentido” Diana de Barros apresenta, seguindo a perspectiva da Semiótica Discursiva francesa, algumas direções teóricas para o estudo dos sentidos da cor. Para realizar tal tarefa, a autora analisa os esmaltes para as unhas. São quatro os principais objetivos de seu texto: examinar as relações entre cromatismo na semiótica do mundo natural e os textos dos esmaltes; observar as relações entre as cores dos esmaltes e os nomes a elas atribuídos e analisar o sincretismo entre o verbal (sonoro) e o visual; tratar dos simbolismos e dos semissimbolismos que se estabelecem nesses textos; por fim, verificar, tomando por base as figuras cromáticas e os nomes das cores (textos verbais), quais imagens de mulher se constroem e quais os valores em jogo. Segundo Barros, o texto das cores do esmalte é um texto sincrético, em que são organizados cores e nomes constituindo uma forma de expressão por meio da substância cromática visual e da substância sonora verbal. Nessa perspectiva, a autora examina o cromatismo do mundo natural e como ele se articula no plano da expressão e no plano do conteúdo. Para tanto, Barros retoma os estudos precursores dos semioticistas JeanMarie Floch e Felix Thürlemann, e também dos pintores Kandinsky e Klee. A autora afirma que as cores estão relacionadas às sensações e ao estado de espírito dos homens e dependem da cultura. Barros considera que, nos estudos de Kandinsky, o pintor discute os sentidos psicológicos das cores e seus efeitos sobre os homens, bem como o papel na diferenciação de culturas.

Em um segundo momento, Barros discorre sobre as cores da língua e considera que o nome das cores, ou seja, os textos verbais resultam da conversão dos traços cromáticos da expressão do mundo natural em traços figurativos, o que produz, no discurso, os efeitos de realidade e de corporalidade. A autora analisa o poema “Os reinos do amarelo”, de João Cabral de Melo Neto, e ressalta, em sua análise, que a construção do tema da miséria e da riqueza é articulada por meio de traços semânticos sensoriais evidentes nos traços cromáticos e de outros elementos do plano da expressão do mundo natural.

Ao basear-se na perspectiva semiótica, na análise dos textos sincréticos do esmalte, a autora afirma que os traços cromáticos são convertidos em traços figurativos, estabelecendo, assim, uma relação de conformidade entre a cor e seu nome. A fim de analisar as cores da mulher, Barros salienta, segundo a abordagem semiótica, a importância dos temas e das figuras adjacentes aos discursos, para pensar a relação cromática dos esmaltes com a figura feminina. 
Segundo a autora, os temas são, segundo a perspectiva semiótica, conteúdos semânticos tratados de maneira abstrata. Já, as figuras são o investimento semântico-sensorial dos temas. Barros afirma que, por meio dos temas e das figuras são criados discursos que representam o modo de ver e de pensar o mundo de grupos e camadas sociais, o que assegura, assim, o caráter ideológico destes mesmos discursos.

Barros finaliza seu capítulo argumentando que os processos de tematização e de figurativização auxiliam no desenvolvimento dos estudos sobre o texto e o discurso, na medida em que contribuem para a construção da significação e do sentido. Por fim, a autora sintetiza que, as cores do mundo, as cores da língua e as cores da mulher revelam como o estudo semiótico da cor e do sentido dos esmaltes leva o pesquisador a conhecer mais sobre os discursos que se reiteram na sociedade, mostrando como a identidade feminina pode se construir e, na mistura de cores, tratar das paixões proeminentes dos discursos dos esmaltes.

Dominique Maingueneau escreve sobre o texto, o gênero, o discurso e a aforização. Para Maingueneau, as noções de texto e de gênero de discurso aparecem indissociáveis, na medida em que um texto pertence a um gênero de discurso, o qual, por sua vez, produz um texto. $\mathrm{O}$ autor se concentra, primeiramente, em enunciados extraídos de um texto. Com base nisso, o autor trata da enunciação aforizante, que, apesar de resistir à lógica do texto e do gênero do discurso, é proferida em um texto. Maingueneau ressalta que o essencial é perceber a tensão que se estabelece entre a aforização e o todo textual. Ao tratar dos dois tipos de aforização, as primárias e as secundárias, Maingueneau considera que, ao lidar com as aforizações primárias, tais como os provérbios, a construção do sentido ocorre com base em um esquema que deve ser aplicado a um número indefinido de situações. Na interpretação das aforizações secundárias, aquelas que são destacadas de um texto, o intérprete é forçado a construir uma alteridade, encontrando o ponto de vista ao qual a aforização se opõe. O autor analisa algumas manchetes de jornal e ressalta que, para realizar tal tarefa, foi necessário mobilizar um determinado enquadramento. Inicialmente, o autor se refere ao enquadramento testemunhal, o qual tende a reduzir a dimensão da informação do texto a favor da expressão de uma emoção ou convicção. Nesse sentido, Maingueneau salienta que a ênfase recai sobre a convicção íntima de um sujeito. Logo adiante em seu texto, o autor trata do enquadramento acional, no qual o aforizador é alguém cujas palavras têm o poder de transformação da realidade.

Ao reiterar os exemplos proeminentes da imprensa escrita, Maingueneau nomeia de regime de memorial aquele em que a aforização é inscrita em uma memória de longa duração. 
Segundo o autor, esse regime manifesta-se a partir de dois tipos de enquadramentos, o histórico e o sapiencial. No enquandramento histórico, a aforização é inseparável de uma narrativa, pois trata-se de uma parte de um acontecimento que se perpetuou como notável.

Maingueneau ressalta que o tipo de interpretação proveniente do enquadramento histórico é muito frequente no campo político. Diferentemente do enquadramento histórico, o autor afirma que o enquadramento sapiencial não é aquele que inscreve a aforização em um acontecimento, mas a apreende como o ponto de vista de um sujeito privilegiado. $\mathrm{Na}$ perspectiva de Maingueneau, esse enquadramento pode se manifestar como moralista ou hermenêutico. Por meio do enquadramento moralista, o autor afirma que a aforização enuncia julgamentos de bom-senso ou paradoxais. No enquadramento hermenêutico, o destinatário explora as potencialidades da enunciação aforizante.

Após tratar destes enquadramentos, Maingueneau conclui seu capítulo considerando que a enunciação aforizante possui sua ordem própria. No entanto, o autor ressalta que toda aforização está englobada em um texto, que pertence a um gênero do discurso. Maingueneau considera que a aforização mantém uma relação privilegiada com a memória e com as formas poéticas da oralidade, manifestando-se de formas variadas segundo as configurações históricas em que pode participar e ser inserida.

No capítulo "Flagrantes da construção interacional dos sentidos”, Ingedore Koch compreende o texto como um construto histórico e social, espaço de interação entre os sujeitos que, dialogicamente, são constituídos por meio de ações linguísticas, sociocognitivas e interacionais. Em seu texto, a autora objetiva apresentar alguns flagrantes de como se efetiva a construção interacional dos sentidos. A autora trata, inicialmente, da referenciação textual, objeto de pesquisa, nas últimas décadas, de autores nacionais e estrangeiros. Koch afirma que a referenciação deve ser compreendida como atividade discursiva, e cita Mondada (2001) que considera a referenciação no âmbito das relações intersubjetivas e sociais em que as visões do mundo são elaboradas em termos das finalidades práticas dos enunciadores.

Koch defende que a discursivização ou a textualização do mundo, por meio da linguagem, não constitui apenas um processo de elaboração de informações, mas sim um processo de reconstrução do próprio real. A autora analisa alguns segmentos a fim de perceber a construção e a reconstrução de referentes. Segundo Koch, uma importante atividade textual e discursiva a ser estudada é a rotulação, a qual consiste no encapsulamento de porções textuais por meio de uma expressão nominal referencial. 
A autora considera que os rótulos contêm um grau de subjetividade e funcionam de maneira metaenunciativa, pois, na medida em que rotulam os segmentos textuais, criam um novo objeto de discurso. Ao analisar alguns exemplos de rotulação, Koch evidencia o importante papel da referenciação das expressões nominais, das anáforas indiretas e do encapsulamento da rotulação para se depreender a produção do sentido na construção argumentativa do texto.

A autora trata, em sequência, da progressão textual e ressalta que a continuidade de um texto resulta da repetição e da progressão. Para retormar uma informação dada anteriormente em um texto, são acionados os mecanismos de remissão ou referenciação. Koch afirma que a estes são acrescentados os mecanismos de progressão textual. A busca de uma progressão favorece a construção de coerência do texto pelo interlocutor. O leitor/ouvinte espera sempre um texto dotado de sentido; com isso, a autora considera que o leitor coloca em funcionamento as estratégias sociocognitivas a fim de dar uma interpretação ao texto.

O último ponto tratado por Koch refere-se à intertextualidade e argumenta que todo texto é um objeto heterogêneo, na medida em que revela a relação de seu interior com o seu exterior. A autora baseia-se nas palavras de Bakhtin (1986), o qual considera que o texto só pode ganhar vida a partir do contato com outro texto. Assim, Koch ressalta que um aspecto importante da intertextualidade é a comparação dos textos produzidos por uma cultura. De tal comparação, torna-se possível inferir as propriedades formais, estilísticas e temáticas comuns a determinados gêneros textuais. Koch conclui que a produção da linguagem está diretamente associada à constante interação do texto com seus interlocutores, constituindo, assim, uma atividade complexa de produção dos sentidos que se realiza não apenas nos elementos linguísticos, mas sobretudo no conjunto de saberes de ordem sociocognitiva, cultural, histórica e de interação verbal.

José Luiz Fiorin discorre sobre a necessidade da distinção entre o texto e o discurso. Fiorin inicia seu texto afirmando que, para muitos estudiosos da linguagem, texto e discurso são sinônimos. O autor considera que o discurso é um objeto linguístico e um objeto histórico. Segundo Fiorin, uma teoria do discurso deve possibilitar a análise do funcionamento discursivo e de sua inscrição histórica. Ao contrapor texto e discurso, o autor afirma que estes dois elementos possuem a propriedade da recursividade. Fiorin ressalta que existem diferenças entre o texto e o discurso, e considera que o primeiro é do domínio da manifestação, enquanto o segundo é da ordem da imanência. 
Fiorin argumenta que um mesmo discurso pode concretizar-se em textos muito diversos. O autor exemplifica essa afirmação ao analisar o poema “Campo de Tarragona”, de João Cabral de Melo Neto. Fiorin compreende o texto e o discurso como produtos da enunciação, e explica ao leitor que ambos diferem quanto ao modo de existência semiótica. Segundo o autor, o discurso e o texto são produtos da enunciação, no entanto, Fiorin considera que eles diferem quanto ao modo de existência semiótica. O discurso é a atualização das virtualidades da língua, ao passo que o texto é a realização do discurso por meio da manifestação.

Com isso, Fiorin considera que, do ponto de vista da estruturação linguística, o discurso é um todo organizado de sentido, pertencente à ordem da imanência, ao plano do conteúdo. O autor afirma ser o discurso a atualização de virtualidades da língua. Segundo o autor, a discursivização opera pelos procedimentos de tematização, figurativização, actoralização, temporalização e espacialização. Por meio destes elementos, Fiorin pontua que é possível inferir que a distinção entre texto e discurso é necessária, na medida em que os procedimentos de discursivização são diversos dos de textualização. Na perspectiva do autor, essa diferenciação decorre pelo texto e o discurso serem objetos com modos de existência semiótica diversa, o texto pertencendo à ordem da manifestação e o discurso à ordem da imanência. Por fim, Fiorin argumenta que: “(...) o texto é a manifestação do discurso por meio de um plano da expressão, o que significa que um mesmo discurso pode ser manifestado por textos diversos” (FIORIN, 2012, p.162).

No capítulo "Por uma análise do discurso multidimensional”, Josiane Boutet busca mostrar como as evoluções da Análise do Discurso e da Sociolinguística fizeram surgir a figura do especialista. Para realizar este estudo, a autora utiliza exemplos do campo especializado da linguagem no trabalho. Inicialmente, Boutet discorre acerca dos estudos no âmbito da Análise do Discurso, e destaca os trabalhos de Michel Foucault e Michel Pêcheux.

A autora distingue dois projetos intelectuais nas ciências da linguagem. O primeiro refere-se ao discurso construído como um objeto teórico, e o segundo trata do discurso concebido como um objeto empírico, baseado em pesquisas de campo. Após as incursões em torno da perspectiva da Análise do Discurso, a autora discorre sobre o desenvolvimento da Sociolinguística, cujo domínio de estudo é constituído pelas línguas e pela linguagem em seu contexto social. Segundo Boutet, a demanda de especializações linguísticas necessitou da construção de projetos multidisciplinares e consistiu em um deslocamento nas maneiras de conceber diferentes objetos de estudo. 
A autora afirma que os resultados das pesquisas, em um método de especialização, são prioritários, ao passo que as preocupações teóricas passam a ocupar um segundo plano. Boutet considera que se ancorar em uma perspectiva multidimensional e plurimetodológica permite atender de forma mais eficaz às demandas da diversidade das pesquisas, dos campos de estudo e das situações sociais. Mais adiante em seu texto, a pesquisadora trata do plano da prosódia, seguindo o quadro teórico de John J. Gumperz, a fim de analisar o nível de competências linguísticas dos atendentes e de alguns centros de atendimentos.

Em sequência, Boutet trata do plano da voz, por meio do quadro de Vygotsky sobre as ligações ontogenéticas entre a linguagem e o pensamento. Por fim, Boutet analisa o plano do léxico e o plano da interação, seguindo a teoria bakhtiniana referente ao universo popular do carnaval e à teoria dos gêneros. Em síntese, a autora considera que a multidimensionalidade da Análise do Discurso pode ser assimilada pelos pesquisadores e atuar na produção de conhecimentos sobre as sociedades globalizadas.

Em “Texto/discurso: qual a relação com a leitura?”, Maria Cecília Souza-e-Silva tece considerações sobre as relações entre texto e discurso, sustentando-se no espaço entre trocas de dois ou mais discursos, ou seja, tomando o interdiscurso como objeto de análise. A autora toma por base a obra Gênese dos discursos (2008), de Maingueneau, delimitando como objeto para análise dois conjuntos de textos cujo tema é o objeto de debate público.

Souza-e-Silva fundamenta-se nos informes de grandes jornais e revistas de circulação nacional, visando a compreender, por meio do interdiscurso, não o estudo de cada discurso isoladamente, mas tendo em vista a relação interdiscursiva que se estabelece entre os textos. A autora trata das identidades discursivas a fim de perceber como é instaurada a polêmica entre dois discursos distintos. Para analisar as identidades discursivas, Souza-e-Silva pontua que é necessário compreender a noção de tema de um discurso, entendido justamente como aquilo que um discurso trata. A autora não apenas faz um levantamento dos temas presentes no texto, mas vislumbra compreender o modo de construção destes temas. Seguindo a análise das reportagens de jornais, a autora sintetiza que, a partir da observação do conjunto dos textos de jornais e revistas, é possível evidenciar que o modelo de coerções proposto por Maingueneau restringe as interpretações de um enunciado. A autora salienta, ao fim de seu texto, que a questão da leitura não se trata apenas de uma questão de texto, mas trata-se da confluência dos campos discursivos e dos espaços discursivos que um texto pode partilhar em diálogo com outros textos. 
Maria Helena de Moura Neves trata da fluidez categorial e da organização textual seguindo a teoria funcionalista da linguagem. A autora propõe reflexões sobre gramática e organização discursivo-textual. Suas bases de análise fundamentam-se na compreensão da língua como estruturações de conteúdos como sistemas de funções, seguindo o pensamento de Coseriu (1979) e, complementarmente, toma como base a noção que Halliday (1994) estabelece como função (o papel da linguagem). Neves complementa suas bases teóricas sustentando-se também nos estudos da Linguística Cognitiva.

A autora aborda a fluidez categorial como característica funcional dos elementos da linguagem e afirma que o campo da linguagem se oferece a categorizações que contribuem para o estabelecimento de categorias rígidas, estanques e definitivas. Neves destaca a importância de se compreender o caráter dinâmico e variável da língua e considera que, nessa linha de reflexão, deve-se ter em vista a importância do processo de gramaticalização, com ênfase nos estudos linguísticos. Em sua amostra de análise, a autora destaca alguns excertos a fim de revelar os campos em que o processo de gramaticalização tem sido buscado.

Como resultados obtidos, Neves destaca quatro pontos fundamentais que aplicou em seus estudos a fim de investigar o processo de gramaticalização. Estes pontos são: 1. Dentro do próprio “léxico”; 2. Na transição do “léxico” para a "gramática”; 3. Dentro da própria “gramática” e 4. Fora do domínio categorial, em uma ampliação da noção de gramaticalização. Assim, a autora ressalta que o objetivo de seu texto foi o de mostrar um panorama de propostas funcionalistas de diferentes vertentes. Ao fixar-se na organização gramatical, Neves visou a defender a necessidade da relativização de fronteiras categoriais no estudo da linguagem, evidenciando os aspectos da gramaticalização na língua em uso.

No capítulo "Interação, texto falado e discurso”, Marli Quadros Leite desenvolve um estudo sobre a interação como fenômeno suscetível de ter desenvolvimento esperado e inesperado. A autora compreende o esperado como aquilo que se enquadra no padrão da interação e no horizonte sociocultural e histórico dos falantes; e entende o inesperado como aquilo que escapa dos padrões ou do horizonte dos interactantes. Seu texto divide-se em duas partes. Na primeira, a autora desenvolve uma reflexão sobre a normatividade que rege o discurso, o qual organiza a representação dos indivíduos nos eventos discursivos que são participantes; na segunda, tem-se a análise do corpus.

Leite trata da normatividade no discurso e tece considerações acerca da noção de norma, seguindo a gramática prescritiva e a Linguística. No entanto, a autora ultrapassa o sentido de 
norma atribuído por estes campos e estende a compreensão de norma para pensar o discurso. A autora fundamenta-se na concepção de Bakhtin sobre o discurso, quando o autor trata da responsividade e da normatividade dos gêneros discursivos. Leite traz ao leitor a seguinte definição de discurso: “O discurso é um lugar abstrato acolhedor e organizador de vozes, ações e costumes, no qual os enunciados se concretizam. É, portanto, um espaço preenchido, mas que se renova sem cessar, sempre com base nas práticas sociais e discursivas” (LEITE, 2012, p. 219). Com base nessa definição, a autora discorre sobre o texto ficcional como uma representação da realidade que trata dos acontecimentos cotidianos compostos por diálogos inerentes aos gêneros discursivos. Assim, Leite ressalta a questão da interação e a analisa em textos como a crônica "Um homem feliz”, de Clarice Lispector, e nas relações de interações do cotidiano das pessoas em um ônibus lotado e em um restaurante.

A análise dos casos selecionados pela autora revelou como a interação constrói conhecimento, na medida em que o ato de enunciar exige que o sujeito se aproprie dos conhecimentos linguísticos e discursivos existentes no mundo. Além disso, Leite conclui, a partir de sua análise, que o trabalho com a prática discursiva revela diferentes maneiras de perceber a interação entre os interactantes de um discurso.

Sírio Possenti escreve algumas notas sobre a língua, o texto e o discurso em seu capítulo. Possenti afirma que seu texto parte de questões inerentes à Análise do Discurso e inicia seu texto ressaltando que um discurso deve prescindir de coerência interna, na medida em que veicula saberes e trata-se de ciências, seguindo a perspectiva de Foucault.

O autor discorre acerca de questões teóricas que envolvem os estudos da Análise do Discurso. Para tanto, Possenti busca explicitar um sentido mais preciso do termo "análise" e considera que as questões metodológicas da Análise do Discurso referem-se, basicamente, à problemática do corpus e à de sua manipulação. A partir da construção de um breve trajeto sobre os estudos da Análise do Discurso, Possenti discorre sobre a língua, o texto e o discurso, visando a retomar as posições mais clássicas da Análise do Discurso. O autor fundamenta-se na concepção de Maingueneau, que afirma que a teoria linguística adotada pelos analistas é dotada de contornos específicos. Possenti ressalta que a Análise do Discurso defende as linguísticas formais e concebe a organização da língua como independente dos sujeitos.

Em sequência, Possenti afirma que o léxico tem importância crucial para o analista do discurso, tendo em vista a tradição semântica, considerando o material linguístico de que é 
composto o campo discursivo. Dessa forma, o autor passa a tratar do texto compreendido como o tipo de unidade característica da produção e da recepção do discurso.

Segundo o autor, o discurso se materializa no texto, e é sua coerência interna que constitui um modo de interpretar o conjunto de elementos textuais, bem como os itens lexicais e a relação com os outros elementos do discurso. Em suas notas sobre a língua, o texto e o discurso, Possenti conclui que este estudo trata de reconhecer as restrições da ordem do discurso, partindo de uma zona de conhecimento particular, além do geral e do individual.

No capítulo "Discurso e produção de conhecimento”, Teun A. Van Dijk faz um resumo de alguns estudos teóricos e empíricos que contribuíram para os estudos do discurso e da ciência cognitiva. Primeiramente, o autor discorre sobre os estudos do discurso, partindo da Sociolinguística, das Gramáticas Tradicionais e das Estruturas Gerativas.

O autor desenvolve considerações a respeito da teoria do conhecimento, afirmando que tanto a Epistemologia clássica quanto a moderna definem o conhecimento como crenças verdadeiras e justificadas. Isso posto, Van Dijk analisou que o estudo psicológico do conhecimento é estabelecido por redes organizacionais de conceitos e categorias presentes na memória semântica. Assim, o autor justifica a necessidade de buscar compreender o discurso e a produção cognitiva em um quadro multidisciplinar, tendo em vista o papel do conhecimento enquanto condição e consequência desses processos. Segundo Van Dijk, a natureza do discurso é multimodal e multinível e a produção de textos ou diálogos é uma prática social específica que se organiza por meio de estruturas semióticas, sintáticas, pragmáticas e interacionais.

O autor considera que as teorias multimodais do conhecimento sugerem os modelos contextuais, definidos como modelos de experiência comunicativa de natureza multimodal. Van Dijk prossegue afirmando que central ao modelo contextual é o mecanismo de conhecimento que cria hipóteses sobre o que os receptores podem ou sabem inferir. O pesquisador considera que a compreensão do discurso tem muitas propriedades em comum com sua produção, pois é um processo embasado no conhecimento da língua e de mundo dos falantes e autores. Ao tratar dos modelos situacionais, Van Dijk afirma que o objetivo da compreensão do discurso não é apenas entender o discurso em si, mas tentar compreender o que ele nos fala sobre alguma situação de mundo. Dessa maneira, além da aquisição de conhecimentos baseada em modelos, o autor infere que novos conhecimentos podem ser produzidos de forma direta, pela descrição geral de eventos, definições de termos ou uso de metáforas. O autor sintetiza que a maioria dos estudos experimentais sobre o papel do conhecimento na produção e compreensão 
do discurso reflete pouco na estrutura e organização do conhecimento na memória. Van Dijk, a fim de analisar como as pessoas adquirem conhecimento por meio dos discursos, considera que se deve conhecer mais acerca da relação entre as estruturas discursivas e as estruturas do conhecimento, considerando as variáveis contextuais que interferem na relação entre o aprendizado, o uso e a reprodução do conhecimento nas sociedades humanas.

Tony Berber Sardinha trata das fórmulas discursivas e da Linguística de Corpus, partindo da noção de fórmulas proposta por Krieg-Planque (2010), que coloca o léxico como elemento principal da Análise do Discurso francesa. Em seu capítulo, o autor trata da relação específica entre a Análise do Discurso francesa e a Linguística de Corpus, buscando evidenciar como conceitos e procedimentos de análise de corpora eletrônicos podem ser úteis para o estudo do discurso, tendo em vista uma perspectiva lexical e computacional. Para realizar seu estudo, Sardinha relata duas pesquisas sobre questões que se relacionam à sociedade e política dos Estados Unidos, tendo por base o Corpus of Historical American English (Coha) e o Corpus of Contemporary American English (Coca). Por meio da análise destas pesquisas, o autor visa a compreender os aspectos discursivos em uma perspectiva da Linguística de Corpus.

Sardinha apresenta o conceito de padronização léxico-gramatical, o qual consiste em palavras recorrentes e estruturas gramaticais como unidades centrais da língua em uso. Além deste conceito, o autor articula a noção de probabilístico e considera que, segundo a Linguística de Corpus, os padrões responsáveis pela formação da linguagem são incontáveis e devem ser atestados por dados obtidos em corpora eletrônicos.

Seu plano de análise se desenvolve tendo por base o exemplo de um programa de tv chamado "Hannity”, do canal Fox News, exibido em 2011. Este programa consiste em uma entrevista entre o apresentador Sean Hannity com Sarah Palin, ex-candidata a vice-presidente na chapa de John McCain, derrotada em 2008 pelo atual presidente dos Estados Unidos, Barack Obama. Sardinha faz a análise dos padrões léxico-gramaticais formados pelos colocado e cria uma tabela organizando os principais lexemas utilizados, a frequência com que foram ditos na entrevista e quais padrões estes lexemas sugerem na produção de sentidos do discurso de cada interlocutor. Além de desenvolver esta relação, o autor produz outras tabelas a fim de perceber como as escolhas lexicais dos participantes da entrevista funcionam na língua inglesa norteamericana. Dessa forma, Sardinha relaciona os lexemas em língua inglesa e suas respectivas significações no nível discursivo. 
Com base nos resultados de sua análise, o autor evidenciou as diferentes perspectivas políticas inerentes aos participantes, que englobam expressões recorrentes do discurso republicano. Além disso, também foi possível perceber o papel da linguagem na comunicação política, visando a refletir sobre um contraponto entre os discursos dos republicanos e democratas. Como resultado de análise, Sardinha cria uma tabela de argumentos empregados que indicam uma prosódia semântica neutra, tendo por preferência o campo de discussão ou argumentação, constituída por elementos que realçam o debate, tornando-o convincente, lógico, persuasivo e acalorado.

Nesta análise, o autor sintetiza que foram empregados recursos argumentativos destinados a criticar o oponente, revelando que a retórica foi a expressão rotulada e metaforizada como um jogo circunscrito à esfera política. Dessa forma, foram evidenciados pelo autor os valores dos republicanos em sua política, tendo em vista o discurso e a produção de sentidos apreendidos pelos padrões léxico-gramaticais. Por fim, o autor desenvolve uma última análise que consiste em candidatos cujos discursos são formados pelo sufixo -ism, de língua inglesa, tais quais a palavra communism (comunismo), socialism (socialismo) e terrorism (terrorismo).

Sardinha distribui os dados colhidos e desenvolve uma pesquisa de base temporal, organizando os lexemas do sufixo -ism em gráficos de décadas, a fim de compreender a ascendência e decadência da forma de pensar em épocas distintas. Assim, o autor faz uma análise de ordenação descendente e a organiza pelas décadas de 1980 e 2000. Por fim, seu capítulo é encerrado revelando que sua pesquisa mostrou maneiras de interpelar corpora eletrônicos com a finalidade de obter candidatos aptos à fórmula e para descrever a riqueza de usos de candidatos, tendo por base a Linguística de Corpus.

Em síntese, o autor estabelece quatro constatações obtidas em suas análises. A primeira consiste na idéia de que a divisão de candidatos com base em períodos de tempo é abalada quando se usa o corpora; a segunda é a afirmação de que a pesquisa com colocados é fundamental para conhecer os sentidos relacionados pelo candidato; a terceira refere-se à análise de cada colocado como um item independente, agregando informações sobre os sentidos das práticas discursivas dos candidatos; a quarta e última constatação de Sardinha é a de que os dados obtidos por corpora grandes como o Corpus of Historical American English (Coha) e o Corpus of Contemporary American English (Coca) exigem que o analista estabeleça uma restrição dos dados analisados. Com isso, o autor buscou ilustrar, em suas pesquisas, como a 
Linguística de Corpus pode oferecer subsídios para a Análise do Discurso, em um panorama amplo e para o estudo das fórmulas, tendo em vista um estudo mais restrito.

Finalmente, com base nos 14 capítulos presentes na obra Texto ou discurso? (2012), é possível ter a oportunidade de conhecer variadas dimensões teóricas e práticas referentes ao texto e ao discurso, por meio de diferentes objetos de pesquisa, escolhas e combinatórias. Esta obra se faz relevante para os estudiosos da linguagem que buscam aprofundar seus conhecimentos em torno das questões sobre o texto e o discurso, tendo em vista os conceitos em discussão nos capítulos decorridos e como estes conteúdos teóricos podem ter sua funcionalidade demonstrada em uma prática de pesquisa.

Verifica-se que a obra Texto ou discurso? (2012) surgiu da necessidade de obter respostas para as problematizações em torno do texto e do discurso. Por meio dos textos de ilustres linguistas brasileiros e de outros países; Beth Brait, Danielle Zaslavsky, Décio Rocha, Diana Luz Pessoa de Barros, Dominique Maingueneau, Ingedore Koch, José Luiz Fiorin, Josiane Boutet, Maria Cecília Souza-e-Silva, Maria Helena de Moura Neves, Marli Quadros Leite, Sírio Possenti, Teun Van Dijk e Tony Berber Sardinha foi evidente a compreensão de que o texto e o discurso apresentam acepções diversas, em diferentes tendências e abordagens.

Com a contribuição das reflexões dessa obra, notou-se que os pontos de vista teóricos e metodológicos diferenciados contribuíram para o sentido criado na interrogação que dá nome ao presente título, objetivando, assim, respostas que fossem representativas das diferentes vozes de distintos locais teóricos, os quais viabilizaram a compreensão das questões acerca do texto e do discurso de forma prática e funcional.

Retrospectiva recebida em: 31.12.2014

Retrospectiva aprovada em: 10.04.2015 